[Type text]

\title{
Thinking as Shaped by Framing Sensitivity
}

\author{
Martin Andersen \\ Linnaeus University \\ Karl Petter Hjelmer \\ Linnaeus University \\ Marcus Selart \\ Norwegian School of Economics
}

Working Paper

Correspondance should be addressed to Marcus Selart, Norwegian School of Economics, Helleveien 30, N-5045 Bergen, Norway. Phone: +47 5595-9695, E-mail:

Marcus.Selart@nhh.no 


\title{
Thinking as Shaped by Framing Sensitivity
}

\begin{abstract}
A major aim of the present study was to investigate effects of sensitivity-to-framing (Witkin's EFT test) on rational and intuitive thinking. A booklet of relevant tests was distributed to university students who served as participants. It was found that field independent participants scored higher on rational thinking tasks than field-dependent participants did. Sensitivity-toframing was also found to be a better predictor of rational thinking than was analytical intelligence. The results are discussed and related to the more general issue how cognitive style may impact upon rational and intuitive thinking.
\end{abstract}

Key words: Cognitive Style, Sensitivity-to-framing, Analytical intelligence, Rational thinking, Intuitive thinking 
Sensitivity-to-framing constitutes a well-known bi-polar and one-dimensional model of cognitive style. It identifies an individual's perceptive behaviour while distinguishing object figures from the content field in which they are set (Witkin, 1973). The content field is a distracting or confusing background. The instrument is designed to distinguish fieldindependent from field-dependent cognitive types; a rating which is claimed to be valueneutral. Field-independent people tend to be more autonomous when it comes to the development of restructuring skills; that is, those skills required during technical tasks with which the individual is not necessarily familiar. They are, however, less autonomous in the development of interpersonal skills.

This form of cognitive style may be denoted as peoples' dependence or independence from their perceptual field and how it impacts their organization of impressions (Witkin \& Asch, 1948; Oltman, Goodenough, Witkin, Freedman \& Friedman, 1975; Goodenough, 1976; Witkin \& Goodenough, 1977; 1981). It is often referred to as sensitivityto-framing, and addresses consistent individual differences with regard to preferred ways of organizing and processing information and experiences (Messick, 1984). Thus, research suggests that this form of cognitive style bridges two important subfields within psychology namely cognition and personality (see also Myers, 1962; Witkin, Moore, Goodenough, \& Cox, 1977; Riding \& Cheema, 1991; Riding \& Sadler-Smith, 1992; Hayes \& Allinson, 1994; Allinson \& Hayes, 1996; Riding, 1997; Sternberg \& Grigorenko, 1997; Hayes \& Allinson, 1998; Riding \& Rayner, 1998; Sadler-Smith \& Spicer, 2000; Sternberg \& Zhang, 2001; Kirton, 2003; Zhang \& Sternberg, 2006; Cools \& Van den Broeck, 2007; Cools, Van den Brouck \& Bouckenooghe, 2009; Zhang \& Sternberg, 2009; Selart, 2010; Zhang, Sternberg, \& Rayner, 2011; Armstrong, Cools \& Sadler-Smith, 2012; Cools, Armstrong \& Verbrigghe, 2014). 
The central idea of this study is to focus on the sensitivity-to-framing and thus build on the older research tradition that has studied the concept of field dependence-independence. It is assumed that the extent to which individuals are susceptible to figure-embedded framing has a bearing on their sensitivity to framing in other more specialized fields, such as reasoning in judgment and decision making tasks. Such framing is often based on the changing of reference points or by manipulating outcome salience and response mode (Tversky \& Kahneman, 1981; Kahneman \& Tversky, 1983; Tversky \& Kahneman, 1986; Entman, 1993; Nelson, Oxley \& Clawson, 1997; Kuhberger, 1998; Levin, Schneider, \& Gaeth, 1998; Kuvaas \& Selart, 2004; Chong \& Druckman, 2007).

A field dependent individual is influenced by the surrounding context and tends to be disturbed by it in the identification of the integrated figures. On the contrary, a field independent individual experiences fewer adaptation problems and may therefore more easily disregard influences from the surrounding context. Accordingly, field independent individuals have shorter response times and are able to detect more embedded figures (Witkin, 1973; Witkin, Moore, Goodenough, \& Cox, 1977).

In this study we will investigate how sensitivity-to-framing influences peoples' performance on analytical reasoning tasks and preference for either analytic or intuitive decision styles. We will also investigate whether sensitivity-to-framing has discriminative validity in relation to analytical intelligence. Our aim is to introduce sensitivity-to-framing as an important predictor of reasoning skills and decision making (see e.g., Stanovich \& West, 1998, 2000).

A test measuring sensitivity-to-framing based on embedded figures was developed in early days by Witkin, Dyk, Fattuson, Goodenough, \& Karp (1962). In this test, participants were introduced to a series of figures integrated into complex pictures where the task consisted of finding the hidden figures. Field dependent and independent individuals have 
been observed to differ from each other in a variety of ways. For instance, field dependent individuals are considered to be more social, group-oriented, and socially competent than field independent individuals (Witkin \& Goodenough, 1981; Witkin, Moore, Goodenough, \& Cox, 1977). They are also assumed to be more sensitive to social interaction and critique, more externally motivated, and to a higher extent dependent on external reference points in managing their social life. Field independent individuals, on the other hand, are often described as more internal in their locus of control, more internally motivated, and more analytically task focused (Fritz, 1994; Liu \& Reed, 1994; Lyons-Lawrence, 1994; Reiff, 1996; Riding \& Cheema, 1991). Evidence from recent studies also suggests that sensitivity-toframing correlates with intelligence, working memory, and verbal/spatial abilities (Jones, 1997; Linn \& Kyllonen, 1981; Lópes-Rupérez, Palacios, \& Sanches, 1991; MacLeod, Jackson, \& Palmer, 1986; McKenna, 1984; Miyake, Witzki, \& Emerson, 2001; Moutier, Angeard, \& Houdé, 2002; Tsaparlis, 2005).

Furthermore, field independent individuals seem to remember more of the surrounding context of an event whereas field dependent individuals are much more attentive to details (Eagle, Goldberger, \& Breitman, 1969).

Based on this reasoning, we make the following two hypotheses:

H1: Field independent individuals will be able to think more rational than field dependent individuals.

H2: Field dependent individuals will report higher levels of intuitive thinking than field independent individuals.

This means that field dependent individuals are assumed to have more difficulty garnering the necessary mental capacity for the controlled cognitive processes associated with analytical decision making. Thus, field dependent individuals should perform less well on these tasks than field independent individuals. 
The Impact of Sensitivity-to-Framing vs. Cognitive Ability on Analytical and Intuitive Decision Processes

Stanovich and West (1998) have found that individual difference with regard to cognitive ability is greatest at a lower algorithmic level. However, individual differences concerning thinking dispositions, at a rational level, are informed by availability to a higher degree. This concept addresses the simplicity by which impressions produced by the situation are perceived. Based on this reasoning, it seems plausible to assume that sensitivity-toframing may better explain differences in both rational and intuitive ability.

Thus, we propose the following:

H3: Sensitivity-to-framing is expected to explain differences in rational and intuitive thinking better than analytical intelligence.

\section{Method}

\section{Participants}

The study was based on responses obtained from 72 students at Linnaeus University who participated voluntarily and without any payment. Participants' ages ranged from 19-40 years $(M=23,5 ; S D=4.16)$. Nearly as many men as women took part in the study, that is, $48.6 \%$ were male and $51.4 \%$ were female. Only two participants did not complete the experiment.

\section{Material}

The present study is based on four tests that measure sensitivity-to-framing, analytical intelligence, self-rated intuition, and rationality. Participants' were also asked about their age and gender.

Part I - Sensitivity-to-framing 
We applied the Gottschaldt test in order to measure sensitivity-to-framing in line with Witkin's development of his Embedded Figures Test. The Gottschaldt test is a paper and pencil test where a participant's task is to find a simple geometric figure in a distractingly complex pattern. This is followed by being asked to mark the figure when it is found. A broad range of such tasks were applied in the test and participants marked as many figures as they were able to perceived during a specified time limit ( 2 minutes per sub-task). Depending on the performance, participants received a variety of scores for the correctly marked figures. They could maximally obtain 47 points. According to Witkin et al. (1962) to be classified as field dependent, participants should lie half a standard deviation below the mean, whereas they should be half a standard deviation above the mean to be classified as field independent $(M=27,4, S D=8.10, N=72)$. Witkin used response latency time per task as his measure of field dependence performance. Instead, we chose to distribute scores depending on the amount of correctly marked figures perceived within a time limit. The aim was to differentiate participants' thinking styles in this connection, since we did not have the time and resources to test each participant with Witkin's method. The internal consistency was high $(\alpha=.84)$.

\section{Part 2 - Analytical Intelligence}

The test we applied in this context is a less advanced and less extensive version of Raven's Advanced Progressive Matrices. It has been used by Mensa Sweden and we had their chairman's approval to use it. Broadly speaking, Raven's matrices are assumed to be reliable in the measurement of analytical intelligence (Carpenter, Just, \& Shell, 1990). Thus we found an internal consistency of .75 using the split-half technique on a pilot group of 40 students. In addition we observed a test-retest reliability of .79 when we retested the material one week later on the same group. These results are very much in line with the reliability results from the Standard Progressive Matrices (SPM). With regard to validity, we have been informed by 
the chairman that the test should correlate between $.75-.82$ with WISC-R scores obtained from a group of students.

The matrices are designed to measure the cognitive processes that, from a theoretical point of view, are assumed to drive general intelligence (Mackintosh, 1998). Recently, Stanovich and West (1998) used this test in order to measure analytical intelligence in their studies on rational thinking. The test that we applied included 18 sub-tasks, and participants could therefore maximally obtain 18 points on the test $(M=9.63, S D=4.35, N=72)$. A time limit of 10 minutes for the entire test was applied. The internal consistency was high $(\alpha=$ $.90)$.

\section{Part 3 - Intuitive Thinking}

The test used in this context was inspired by a test developed by Adelbratt (2004) measuring self-rated intuition in decision situations. In our test, participants were introduced to a series of everyday decision situations related to personal relationships, education, job alternatives, personal finances etc. The participants' task is to indicate to what degree they used their intuition/gut feeling in the presented six situations. A Likert Scale with seven levels was used to measure responses. The lowest degree of intuition (Not at all) rendered 1 point whereas the highest degree (Exclusively) rendered 7 points. This implied a maximum score of 42 points $(M=27.8, S D=3.9, n=50)$. The internal consistency was in the lower range of what may be regarded as acceptable $(\alpha=.81)$.

\section{Part 4 - Analytical thinking}

The rationality test consists of two separate parts, focusing on syllogisms and statistical reasoning. The syllogism tasks should be solved by taking into account deductive reasoning. These tasks include two premises and one conclusion. Premises and conclusions are not always obtained from the real world to test the ability to think logically (ex. premises: P1 All leaders are managers, P2 Mahatma Gandhi was a leader, Conclusion: Mahatma Gandhi was a 
manager). Hence, the goal was to judge whether or not the conclusion was logically correct or incorrect on the basis of the premises, without being influenced by the real world appearance of the latter. The syllogism test was based on a study presented by Markovits and Nantels (1989) that also served as inspiration for Stanovich and West (1998). Each correct answer rendered a score of one and incorrect answers resulted in a score of zero.

The test of statistical reasoning, on the other hand, is based on inductive reasoning and has also been previously used by Stanovich and West (1998) as stimulus material. The test was modified such that it would suite Scandinavian conditions. Hence, six decision scenarios were created where each task described a bipolar decision situation where one of the situations was supported by a statistical majority and the other was more individual and based on a subjective opinion. Each task included four rating scale options including the two end poles. Participants received scores depending on the extent to which their responses coincided with the statistical majority options. Four levels of scores were distributed (Alternative A, most certainly $=2$; Alternative A, probably $=1.5$; Alternative $\mathrm{B}$, probably $=0.5$; Alternative $\mathrm{B}$, most certainly $=0$ ) such that the highest levels represented the statistical majority options and the lowest denoted the individual and subjective options. The results from the two separate rationality tests were added in order to obtain a maximal total rationality score of 22 points (syllogisms: $\max 10$ points; statistical reasoning: $\max 12$ points) ( $n=72, M=13.96$, $S D=3.12)$.

\section{Procedure}

A series of pilot tests was conducted in order to create a booklet of reliable tests. These tests were subsequently conducted in two larger classes including undergraduate psychology students. The entire sessions lasted for about 30-40 minutes and specific time restrictions were imposed on the two introductory cognitive tests (cognitive style and analytical intelligence). The cognitive style test included five subtests that each had a time restriction set 
to two minutes. In the remaining three tests, (intuition, syllogisms, and statistical reasoning), no time restrictions were applied. Here, participants could use as much time as they wanted to fulfil the tasks. An experiment leader was always present during the sessions in order to assist and make oral clarifications. Before submission, all participants were instructed to check that all items had been properly filled in.

\section{Results}

Our first hypothesis implies that field dependent individuals will be better rational performers than framing susceptible ones. This hypothesis was tested by using a one way ANOVA with sensitivity-to-framing (field dependent, field independent) as the independent variable and rationality scores as the dependent variable $\left(F(1,46)=24.16, p<.001, \eta^{2}=.354\right)$. A reliable main effect was detected indicating support for Hypothesis 1 (see Figure 1 for a graphical illustration).

Figure 1 about here

Our second hypothesis states that field dependent individuals should use intuitive reasoning processes to a higher extent than field independent individuals. This hypothesis was tested with a one way ANOVA with sensitivity-to-framing (field dependent, field independent) as the independent variable and self rated intuition as the dependent variable ( $F$ $\left.(1,40)=6.81, p<.10, \eta^{2}=.12\right)$. A marginally reliable main effect was observed in support of Hypothesis 2 (see Figure 2 for a graphical illustration).

Figure 2 about here

Our third hypothesis suggests that sensitivity-to-framing should better predict the dependent variables than analytical intelligence. In order to establish this, we first performed a correlation analysis of all the main variables (see Table 1).

Table 1 about here 
Second, this hypothesis was tested with two step-wise multiple regression analyses (MRAs). In the first analysis, rationality was used as the criterion (dependent) variable and analytical intelligence and cognitive style were applied as the independent variables, while controlling for age and gender (see Table 2). Here, two reliable predictors were found to better explain the variance observed in the dependent variable than analytical intelligence, namely cognitive style $(\beta=.56, p<.0 .001)$ and age $(\beta=.22, p<.05)$. Analytical intelligence only revealed a weak tendency to become significant $(\beta=.17, p=.12)$. The collinearity between sensitivity-to-framing and analytical intelligence was tested as a manipulation check and revealed a correlation of $r=.383, p<0.001$. This result was judged as satisfactory as the critical limit value is normally set to somewhere in between .60 and .70 .

Table 2 about here

In the second stepwise multiple regression analysis we applied the same predictors but used self-rated intuition as the criterion (dependent) variable. Here, neither sensitivity-toframing nor analytical intelligence was able to predict self-rated intuition reliably. (see Table 3). However, age did predict self-rated intuition $(\beta=-.36, p<.01)$.

Table 3 about here

Gender as a covariat to cognitive style

In an analysis of covariance (ANCOVA) gender was tested as a covariat to sensitivityto-framing as the independent variable and rationality as the dependent one. Here, it was revealed that gender was a marginal explanator of the results revealed in connection with the test of Hypothesis $1\left(F(1,46)=21.24, p<.001, \eta^{2}=.33\right)$.

\section{Discussion}

The main purpose of the present study was to investigate the importance of sensitivityto-framing on rational performance and self-rated intuition. Another important aim was to 
clarify if sensitivity-to-framing would better predict rationality and intuitive processing than analytical intelligence. The results clearly indicated a difference in how field dependent and field independent individuals perform rationally and intuitively. Sensitivity-to-framing was found to be a better predictor of rational performance than analytical intelligence. Additionally, sensitivity-to-framing was perceived to be a better predictor of self-rated intuition than was analytical intelligence.

During the last decade, there have been numerous studies that have looked at the impact of thinking style and cognitive capacity on peoples' reasoning and decision making (e.g., Stanovich \& West, 1998, 2000). Most often, the need for cognition (NfC) has been chosen as the focal thinking style. However, the predictive power of NfC on peoples' reasoning skills has been difficult to establish in these studies. The contribution of the present paper lies in the identification of sensitivity-to-framing as a quite good predictor of reasoning skills and decision making. Additionally, findings from previous research establishing strong correlations between sensitivity-to-framing and analytical intelligence (e.g., Linn \& Kyllonen, 1981; Lópes-Rupérez, Palacios, \& Sanches, 1991; Tsaparlis, 2005) have been replicated. Furthermore, we have extended this research through showing that sensitivity-to-framing seems to be related to both analytical and intuitive decision making in a rather systematic way.

Sensitivity-to-framing appears to better than intelligence be able to predict reasoning skills and analytical decision making. A parallel may be drawn to the area of inhibition. It has been shown lately that inhibitory capacity tests can be a better predictor of reasoning performance than more general ability tests (e.g., Markovits \& Doyon, 2004). A clear-cut relationship between inhibition training and field dependence has also been observed (Moutier, Angeard, \& Houdé, 2002). Thus, inhibition may, like field dependence, include a broader range of complex capabilities in comparison to analytical intelligence. For instance, 
an interesting issue to consider could be how field dependence is connected to inhibition, since there are indeed many similar traits.

The obtained results were clearly in support of Hypothesis 1. Field independent individuals performed significantly better on the rationality tasks than field dependent individuals. In order to perform well on our rationality test (syllogisms and statistical reasoning) the ability to de-contextualize the logics and find the primary problems in the presented information appears to be crucial (Stanovich \& West, 1998). An interpretation of why sensitivity-to-framing correlates more with the rational thinking test than does the Raven thus suggests that field dependence is indistinguishable from spatial ability. So, the correlation between sensitivity-framing and rational thinking could largely be mediated by a shared component of spatial ability (see also Chater, 1996, 1997, 1999; Chater \& Vitanyi, 2003).

However, Hypothesis 2 was only marginally supported. Our results revealed that sensitivity-to-framing also leads to differences in self-rated intuition but the effect was found only to be marginally reliable. Here, field dependent individuals reported a higher degree of self rated intuition than what field independent individuals did. However, this finding only revealed a very marginal significance. This tendency may therefore be regarded as a hypothesis which has not yet been falsified and would be a reasonable work hypothesis for future studies. An explanation of this tendency could be that field independent individuals tend to select more analytical decision strategies (lower scores on the intuition test) in order to deliberately assure themselves that they have chosen the best possible alternative. As field dependent individuals performed worse on the rationality test, it may be assumed that they prefer to apply their intuitive capabilities (higher score on the intuition test) rather than more analytically and reason-based approaches. Several studies confirm that field independent individuals are more task oriented, more attentive to detail, and more analytical than field 
dependent individuals (Chinien \& Boutin, 1992, 1993; Fritz, 1994; Liu \& Reed, 1994; LyonsLawrence, 1994; Reiff, 1996; Riding \& Cheema, 1991). It may be suggested that field dependent and field independent individuals are implicitly or explicitly aware of their rational and analytical capacity and tend to select their level of applied intuition accordingly.

Finally, we received mixed support for Hypothesis 3. Sensitivity-to-framing was revealed to be a better predictor of rational performance than analytical intelligence. This result may be interpreted such that sensitivity-to-framing includes a broader range of complex capabilities compared with analytical intelligence. This fact should explain the difference with regard to rational performance. There are several studies that support this interpretation revealing high degrees of correlation between cognitive style and several other cognitive abilities (Elliott, 1961; Jackson, 1956; Sternberg, 1997). However, our results showed that neither sensitivity-to-framing nor analytical intelligence was able to predict self rated intuition. Nevertheless, a marginal ability was observed for sensitivity-to-framing. It is possible that this ability could have been verified if we had not operationalized at such a general level.

\section{Limitations}

Our test of sensitivity-to-framing had very high reliability, with a good distribution. Nevertheless, our time pressure and scoring procedures may be questioned, since they have not been tried before. Still, the results, in this context, seem to indicate a good distinction between participants' performances. The test of analytical intelligence also received high reliability scores with a good distribution. We decided to apply only one test of analytical intelligence in order to better be able to focus on the relationship between sensitivity-toframing and analytical intelligence. Another reason was to limit the use of tests in the entire 
study. Given this, we only used the instrument in order to measure the analytical part of intelligence, which is part of general intelligence.

With regard to our intuition test, it must be revealed that the concept was difficult to operationalize, since intuition is built on individual experiences and is not open for introspection. For this reason, it became too complicated to test intuitive performance. Instead, we tested participants' attitudes toward using their intuition in a couple of scenarios. Through this, we obtained indirect measures on their use of intuition.

Focusing on the test of rational performance, we relied to a great extent on material developed by Stanovich and West (1998). Since this test material has been used to a large degree by other scientists, and is widely cited, reliability has been externally established and recognised. Consequently, we believe that we can rely on the two tests of theirs that have been applied in our study. It is important to note, however, that our measure of rationality only rests on syllogisms and statistical reasoning. We would have optimally liked to have applied more dimensions of rationality, in line with Stanovich and West. Nevertheless, in order to limit our general number of tests, we believed it to be satisfactory to test inductive and deductive reasoning (statistical reasoning vs. syllogisms) as a means to measure rational performance in a reliable way.

Another issue is that we only used a limited section of a full scale IQ test and that the validity of this section only has only been partially established (Ravens matrices). For this reason, it may be argued that the criticism directed towards IQ tests lacks validity. However, it must be noted that Ravens' matrices have been used extensively in practical settings as a useful assessment tool for IQ. The Progressive Matrices have been described as one of the purest and best measures of $\mathbf{g}$ or general intellectual functioning, available.

Finally, it must be noted that the present study is purely correlational and do not provide any experimental support. For instance, the original Stanovich and West studies have recently 
been followed-up by secondary task studies that showed that a lack of executive resources is directly causing faulty analytic reasoning and decision making (de Neys, 2006).

\section{Future research}

A great challenge lies in trying to establish the effect of sensitivity-to-framing on intuitive decision making. The present results only give an indication of a partial connection, and the scale measuring self-reported intuition has not yet been thoroughly validated. If this connection could be more fully established it would give further support for the notion that the availability heuristic (Kahneman, 2003; Selart, Kuvaas, Boe, \& Takemura, 2006) plays a major part in explaining the influence of sensitivity-to-framing on analytical and intuitive decision making.

It would also be interesting to study the role of syllogisms more in detail. An important division may be made between abstract syllogisms and syllogisms with a belief-logic conflict. Stanovich and West have used both types in their studies. Focusing on belief-laden syllogisms, it would be perfectly possible to partial out the effects of logic and believability on two separate indices (e.g., see Newstead, Handley, Harley, Wright, \& Farrelly, 2004). In such a case, field independent individuals should score higher on the logical index whereas field dependent individuals should score higher on the belief-based index. Such results would in many ways clarify the relation between field dependence and inhibition.

Implications for practice.

The findings in this study have several possible implications for practice. Organizations seek to hire and promote individuals with solid analytical decision making skills (Hunt, Krzystofiak, Meindl, \& Yousry, 1989; Chan, 1996; Graff, 2003; Sadler-Smith \& Smith, 2004; Kozhevnikov, 2007). Some companies explicitly test for reasoning abilities or even intelligence. This study shows that field dependence does explain a sizable portion of the 
variation in performance on analytical skills. Moreover, we have demonstrated that field dependence shows discriminative validity in relation to intelligence.

However, intelligence testing has been criticized for assessing limited and in some cases irrelevant skills when applied to real life contexts. Other criticisms are that intelligence tests are too elementary and fail to capture cognitive creative problem solving capabilities by asking people to choose one correct answer (Menkes, 2005).

In contrast to intelligence tests, tests of sensitivity-to-framing provide an indication of peoples' ability to de-contextualize; an ability that is immediately useful in real life, as people in everyday life are forced to absorb and digest vast amounts of information. How people handle information and their ability to apply analytical thinking in situations where there exist an abundance of (sometimes) superfluous information is most likely highly relevant to how an employee performs in his or her job. For instance, it has been shown by Hodgkinson, Bown, Maule, and Glaister (1999) that the framing bias is likely to be an important factor in judgment and decision making and the ability to work with cognitive mapping provides an effective means of limiting the damage accruing from this bias.

A second implication is that people depending on their sensitivity-to-framing seem to apply different strategies of decision making. If field dependent individuals apply different tactics and strategies from field independent individuals, this knowledge would be useful for organizations to better assist employees in improving on their analytical and decision making skills. Field dependent individuals may through training become better at de-contextualizing information and thus become better at their decision making skills, or they may, by becoming aware of their cognitive style, develop meta-skills by which they are able to monitor and choose optimal strategies based on their cognitive style. According to Klein (1998), it is important that people in organizations understand that the perspective that they employ provides a set of values and salient issues that influence the factors that we consider in our 
decision-making processes. As a result it influences our final choice. Field dependent decision-makers train themselves in developing a full understanding of the situation by explicitly viewing decision problems from divergent perspectives. Such different frames may, for instance, include an engineering/technology frame, a sales/marketing frame, a production frame, a political frame, a legal frame, an accounting/finance frame, a competitive frame, and an ethical frame.

Finally, there may be tasks and areas in which field dependents excel. The creativity research literature thus emphasizes the role of intuition in producing novel and creative ideas. Highly creative people have been found to be highly receptive to contextual cues just like field dependent individuals. Testing people for field dependence then may be used to place people in areas in which these specific skills are likely to be particularly useful and in which the possible drawbacks from field dependence are less prominent.

Rather than seeing either analytical or intuitive strategies as superior to each other, optimal strategies may combine these strategies and apply them to different stages in a decision making process. Nevertheless, how such combinations are achieved will depend on how sensitivity-to-framing is perceived. If sensitivity-to-framing is found to be a fixed personality trait, combinations will have to be achieved through the composition of work groups. If sensitivity-to-framing can be taught or influenced, individuals may be able to adapt their sensitivity-to-framing to different problems.

\section{References}

Adelbratt, T. (2004). Everyday notions of good decision making: Theoretical and practical implications. Göteborg University Dissertation Series. 
Allinson, C. W., \& Hayes, J. (1996). The cognitive style index: A measure of intuitionanalysis for organisational research. Journal of Management Studies, 33, 119-135.

Armstrong, S. J., Cools, E., \& Sadler-Smith, E. (2012). Role of cognitive styles in business and management: Reviewing 40 years of research. International Journal of Management Reviews, 14, 238-262.

Carpenter, P. A., Just, M. A., \& Shell, P. (1990). What one intelligence test measures: A theoretical account of the processing in the Raven Progressive Matrices Test. Psychological Review, 97, 404-431.

Chan, D. (1996). Cognitive misfit of problem-solving style at work: A facet of personorganisation fit. Organizatuional Behavior and Human Decision Processes, 68, 194-207.

Chater, N. (1996). Reconciling simplicity and likelihood principles in perceptual organization. Psychological Review, 103, 566-581.

Chater, N. (1997). Simplicity and the mind. The Psychologist, 10, 495-498.

Chater, N. (1999). The search for simplicity: A fundamental cognitive principle? The Quarterly Journal of Experimental Psychology Section A, 52, 273-302.

Chater, N., \& Vitanyi, P. (2003). Simplicity: A unifying principle in cognitive science. Trends in Cognitive Science, 7, 19-22.

Chong, D., \& Druckman, J. N. (2007). Framing theory. Annual Review of Political Science, 10, 99-118.

Cools, E., Armstrong, S. J., \& Verbrigghe, J. (2014). Methodological practices in cognitive style research: Insights and recommendations from the field of business and psychology. European Journal of Work and Organizational Psychology, 23, 627-641. 
Cools, E., \& Van den Broeck, H. (2007). Development and validation of the cognitive style indicator. The Journal of Psychology, 141, 359-387.

Cools, E., Van den Brouck, H., \& Bouckenooghe, D. (2009). Cognitive styles and person-environment fit: Investigating the consequenses of cognitive (mis)fit. European Journal of Work and Organizational Psychology, 17, 33-54.

Eagle, M., Goldberger, L., \& Breitman, M. (1969). Field dependence and memory for social vs. neutral and relevant vs. incidental stimuli. Perceptual \& Motor Skills, 29, 903910.

Elliott, R. (1961). Interrelationships among measures of field dependence, ability and personality traits. Journal of Abnormal and Social Psychology, 63, 27-36.

Entman, R. M. (1993). Framing: Toward clarification of a fractured paradigm. Journal of Communication, 43, 51-58.

Fritz, R. L. (1994). Gender differences in field-dependence and educational style. Journal of Vocational Education Research, 19(1), 1-21.

Goodenough, D.R. (1976). The role of individual differences in field dependence as a factor in learning and memory. Psychological Bulletin, 83, 675 - 694.

Graff, M. (2003). Learning from web-based instructional systems and cognitive style. British Journal of Educational Technology, 34, 407-418.

Hayes, J., \& Allinson, C. W. (1994). Cognitive style and its relevance for management practice. British Journal of Management, 5, 53-71.

Hayes, J., \& Allinson, C. W. (1998). Cognitive style and the theory and practice of individual and collective learning in organizations. Human Relations, 51, 847-871. 
Hodgkinson, G. P., Bown, N. J., Maule, A. J., Glaister, K. W., Pearman, A. D. (1999). Breaking the frame: An analysis of strategic cognition and decision making under uncertainty. Strategic Management Journal, 20, 977-985.

Hunt, R. G., Krzystofiak, F. J., Meindl, J. R., \& Yousry, A. M. (1989). Cognitive style and decision making. Organizational Behavior and Human Decision Processes, 44, 436-453.

Jackson, D. (1956). A short form of Witkin's Embedded Figures Test. Journal of Abnormal and Social Psychology, 3, 254-255.

Jones, A. E. (1997). Field dependence: an evaluation of issues for education and psychology, $\mathrm{Ph}$. D. Thesis, University of Lancaster, England.

Kahneman, D. (2003). A perspective on judgment and choice: Mapping bounded rationality. American Psychologist, 58, 697-720.

Kahneman, D., \& Tversky, A. (1983). Choices, values, and frames. American Psychologist, 39, 341-350.

Kirton, M. J. (2003). Adaptation and Innovation in the Conxtext of Diversity and Change. London: Routledge.

Klein, G. (1998). Sources of power: How people make decisions. Cambridge, MA: MIT Press.

Kozhevnikov, M. (2007). Cognitive styles in the context of modern psychology: Toward an integrated framework of cognitive style. Psychological Bulletin, 133, 464-481.

Kuhberger, A. (1998). The influence of framing on risky decisions: A meta-analysis. Organizational Behavior and Human Decision Processes, 75, 23-55.

Kuvaas, B., \& Selart, M. (2004). Effects of attention framing on cognitive process and evaluation. Organizational Behavior and Human Decision Processes, 95, 198-207. 
Levin, I. P., Schneider, S. L., \& Gaeth, G. J. (1998). All frames are not created equal: A typology and critical analysis of framing effects. Organizational Behavior and Human Decision Processes, 76, 149-188.

Linn, M. C. \& Kyllonen, P. (1981). The field dependence-independence construct: some, one, or none? Journal of Educational Psychology, 73, 261-273.

Liu, M., \& Reed, W. M. (1994). The relationship between the learning strategies and learning styles in a hypermedia environment. Computers in Human Behavior, 10, 419-434.

López-Rupérez, F., Palacios, C., \& Sanchez, J. (1991). Relation of field independence and test-item format to student performance in written Piagetian tests. Journal of Research in Science Teaching, 28, 389-400

Lyons-Lawrence, C. L. (1994). Effect of learning style on performance in using computer based instruction in office systems. The Delta Psi Epsilon Journal, 36, 166-175.

McKenna, F. P. (1984). Measures of field dependence: cognitive style or cognitive ability? Journal of Personality and Social Psychology, 47, 593-603.

Mackintosh, N. J. (1998). IQ and Human Intelligence. Oxford University Press: Oxford.

MacLeod, C. M., Jackson, R. A., \& Palmer, J. (1986). On the relation between spatial ability and field dependence. Intelligence, 10, 141-151.

Markovits, H., \& Doyon, C. (2004). Information processing and reasoning with premises that are empirically false: Interference, working memory, and processing speed. Memory \& Cognition, 32, 592-601.

Markovits, H., \& Nantel, G. (1989). The belief-bias effect in the production and evaluation of logical conclusions. Memory \& Cognition, 17, 11-17.

Menkes, J. (2005). Hiring for smarts. Harvard Business Review, 83, 100-109. 
Messick, S. (1984). The nature of cognitive styles: problems and promises in educational research. Educational Psychology, 19, 59-74.

Miyake, A., Witzki, A. H., \& Emerson, M. .I. (2001). Field dependence-independence from a working memory perspective: a dual task investigation of the Hidden Figures Test. Memory, 9, 445-457.

Moutier, S., Angeard, N., \& Houdé, O. (2002). Deductive reasoninng and matching-bias inhibition training: Evidence from a debiasing paradigm. Thinking \& Reasoning, 8, 205-224

Myers, I. B. (1962). Manual: The Myers Briggs Type Indicator. Palo Alto, CA: Consulting Psychologist Press.

Nelson, T. E., Oxley, Z. M., \& Clawson, R. A. (1997). Toward a psychology of framing effects. Political Behavior, 19, 221.246.

de Neys, W. (2006). Dual processing in reasoning - Two systems but one reasoner. Psychological Science, 17, 428-433.

Newstead, S. E., Handley, S. J., Harley, C., Wright, H., \& Farrelly, D. (2004). Individual differences in deductive reasoning. Quarterly Journal of Experimental Psychology A-Human Experimental Psychology, 57, 33-60.

Oltman, P.K., Goodenough, D.R., Witkin, H.A., Freedman, N., \& Friedman, F. (1975). Psychological differentiation as a factor in conflict resolution. Journal of Personality and Social Psychology, 32, 730 - 736.

Reiff, J. (1996). At-risk middle level students or field dependent learners. Clearing House, 69, 231-234.

Riding, R. J. (1997). On the nature of cognitive style. Educational Psychology, 17, 2949. 
Riding, R. J., \& Cheema, I. (1991). Cognitive styles: An overview and integration. Educational Psychology, 11, 193-215.

Riding, R. J., \& Rayner, S. G. (1998). Cognitive Style and Learning Strategies. London: David Fulton Publishers.

Riding, R. J., \& Sadler-Smith, E. (1992). Type of instructional material, cognitive style, and learning performance. Educational Studies, 18, 323-340.

Sadler-Smith, E., \& Smith, P.J. (2004). Strategies for accommodating individuals' styles and preferences in flexible learning programmes. British Journal of Educational Technology, $35,395-412$.

Sadler-Smith, E., Spicer, D. P., \& Tsang, F. (2000). Validity of the Cognitive Style Index: Replication and extension. British Journal of Management, 11, 175-181.

Selart, M. (2010). A Leadership Perspective on Decision Making. Oslo: Cappelen Damm.

Selart, M., Kuvaas, B., Boe, O., \& Takemura, K. (2006). The influence of decision heuristics and overconfidence on multiattribute choice: A process-tracing study. European Journal of Cognitive Psychology, 18, 437-453.

Stanovich, K. E., \& West, R. F. (1998). Individual Differences in Rational Thought. Journal of Experimental Psychology: General, 127, 161-188.

Stanovich, K. E., \& West, R. F. (2000). Individual differences in reasoning: Implications for the rationality debate? Behavioral and Brain Sciences, 23, 645-726.

Sternberg, R. J. (1997). Thinking Styles. Cambridge: Cambridge University Press.

Sternberg, R. J. \& Grigorenko, E. L. (1997). Are cognitive styles still in style?, American Psychologist, July, 700-12. 
Sternberg, R. J., \& Zhang, L. F. (2001). Perspectives on Thinking, Learning, and Cognitive Styles. Mahwah, NJ: Lawrence Erlbaum.

Tsaparlis, G. (2005). Non-algorithmic quantitative problem solving in university physical chemistry: A correlation study of the role of selective cognitive factors. Research in Science and Technology Education, 23, 125-148.

Tversky, A., \& Kahneman, D. (1981). The framing of decisions and the psychology of choice. Science, 211, 453-458.

Tversky, A., \& Kahneman, D. (1986). Rational choice and the framing of decisions. The Journal of Business, 59, 251-278.

Witkin, H. A. (1973) The role of cognitive style in academic performance and in teacher- student relations. Princeton, NJ: ETS

Witkin, H A. \& Asch, S. E. (1948). Studies in space orientation: Perception of the upright in the absence of visual field. Journal of Experimental Psychology, 38, 603-6 14.

Witkin, H. A., Dyk, R. B., Fattuson, H. F., Goodenough, D. R., \& Karp, S. A. (1962). Psychological differentiation: Studies of development. New York: Wiley.

Witkin, H. A., \& Goodenough, D. R. (1977). Field dependence and interpersonal behaviour. Psychological Bulletin, 84, 661-689.

Witkin, H. A., \& Goodenough, D. R. (1981). Cognitive styles: essence and origins. New York: International Press

Witkin, H. A, Moore, C. A. , Goodenough, D. R. \& Cox, P. W. (1977). Field-depentent and field-independent cognitive styles and their educational implications. Review of Educational Research, 47. 1-64.

Zhang, L. F., \& Sternberg, R. J. (2006). The Nature of Intellectual Styles. Mahwah, NJ: Lawrence Erlbaum. 
Sensitivity-to-Framing 26

Zhang, L. F., \& Sternberg, R. J. (2009). Perspectives on the Nature of International Styles. New York: Springer

Zhang, L. F., \& Sternberg, R. J. (2011). Handbook on Intellectual Styles: Preferences in Cognition, Learning, and Thinking. New York: Springer.

Table 1.

A correlational analysis (Pearson) of the main variables $(\mathrm{N}=72)$ 
Sensitivity-to-Framing 27

\begin{tabular}{lcccc} 
Variables & 1 & 2 & 3 & 4 \\
\hline 1.Field dependence-independence & - & $.383^{* *}$ & -.130 & $.555^{* *}$ \\
2. Intelligence & - & .019 & $.360^{* *}$ \\
3. Intuition & & - & -.204 \\
4. Analytical decision making & & &
\end{tabular}

$* *_{\text {significant, }}<<, 01 . *$ significant, $\mathrm{p}<, 05$.

\section{Table 2.}

A multiple step-wise regression analysis based on predictors of rationality $(n=67)$ 


\begin{tabular}{|c|c|c|c|}
\hline Variables & $B$ & $\beta$ & $p$ \\
\hline \multicolumn{4}{|l|}{ Step 1} \\
\hline Cognitive style & $.21(.04)$ & .56 & $<.001$ \\
\hline \multicolumn{4}{|l|}{ Excluded Variables } \\
\hline Analytical Intelligence & & .17 & .12 \\
\hline Gender & & -.07 & .53 \\
\hline Age & & .22 & .04 \\
\hline \multicolumn{4}{|l|}{ Step 2} \\
\hline Cognitive style & $.23(.04)$ & .59 & $<.001$ \\
\hline Age & $.17(.08)$ & .22 & .04 \\
\hline \multicolumn{4}{|l|}{ Excluded Variables } \\
\hline Analytical Intelligence & & .18 & .09 \\
\hline Gender & & -.06 & .59 \\
\hline
\end{tabular}

Note: $B$ is a non-standardized regression coefficient with the standard error in parantheses; $\beta$ is the standardized regression coefficient; $R=.56, R^{2}=.31, F=29.45, p<.001$ for Step $1 ; R=$ $.60, R^{2}=.35, F=17.81, p<.001$ for Step 2 .

Table 3.

A multiple step-wise regression analysis based on predictors of self-rated intuition $(n=49)$ 


\begin{tabular}{llll}
\hline Variables & $B$ & $\beta$ & $p$ \\
\hline Step 1 & & & \\
Age & $-.48(.18)$ & -.36 & .01
\end{tabular}

Excluded Variables

Cognitive style

Analytical Intelligence

Gender
$-.17$ .15

.01

.96

.22

.36

Note: $B$ is a non-standardized regression coefficient with the standard error in parantheses; $\beta$ is the standardized regression coefficient; $R=.36, R^{2}=.13, F=7.20, p=.01$ for Step 1 


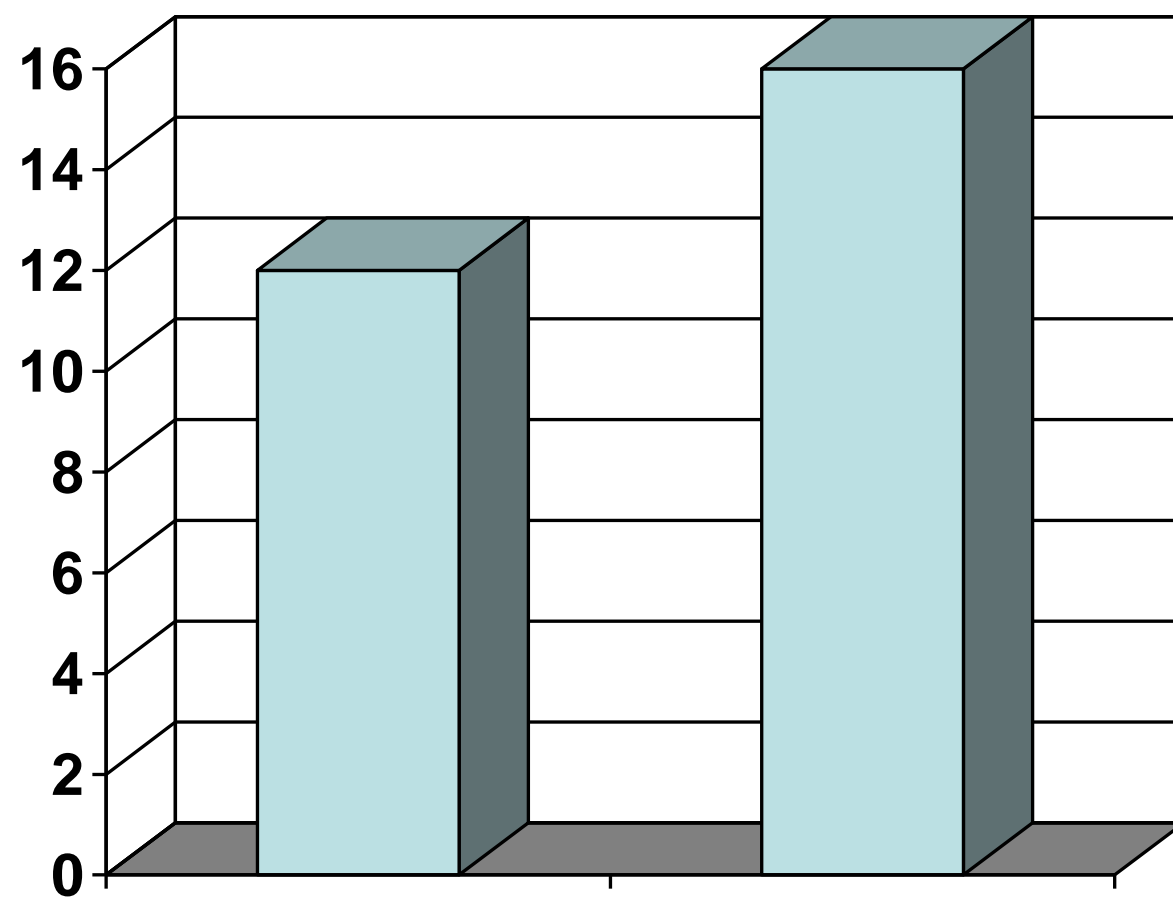

$\square$ Rationality Scores

Field Dependent Field Independent

Figure 1. Mean scores of Field Dependent Individuals $(\mathrm{n}=22)$ and Field Independent Individuals $(n=24)$ with regard to rationality 


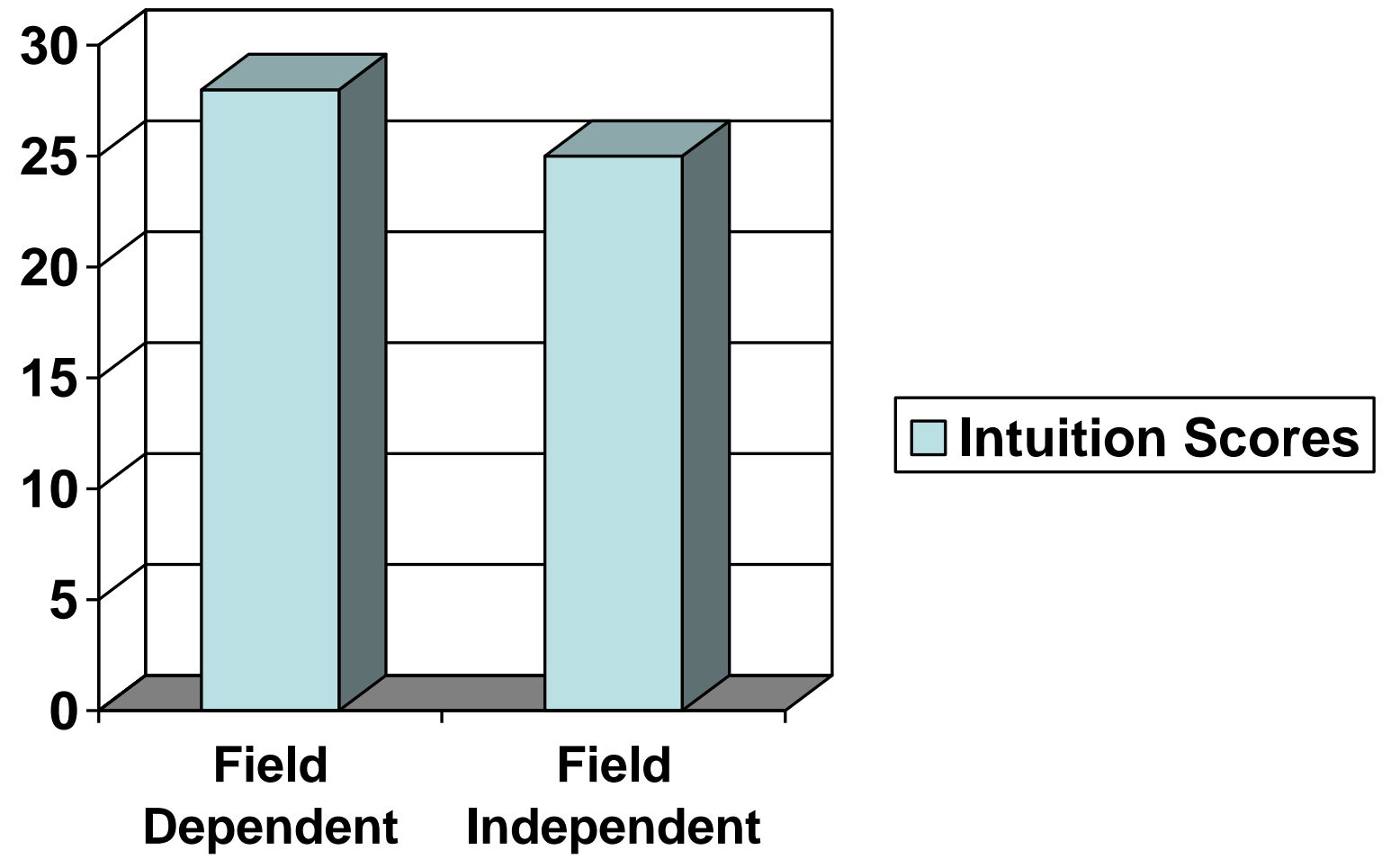

Figure 2. Mean scores of Field Dependent Individuals $(\mathrm{n}=15)$ and Field Independent Individuals $(n=15)$ with regard to self-rated intuition 